\title{
PENGARUH PENDIDIKAN KESEHATAN TERHADAP TINGKAT PENGETAHUAN HAND HYGIENE PADA ANAK SEKOLAH DASAR DI KELAS IV DAN V SEKOLAH DASAR NEGERI 169 PALEMBANG TAHUN 2019
}

\author{
Fera Siska \\ Program Studi DIII Keperawatan STIKES Mitra Adiguna Palembang \\ Komplek Kenten Permai Blok J No 9-12 Bukit Sangkal Palembang 30114 \\ Email : feesiska@gmail.com
}

\begin{abstract}
Abstrak
Hygiene adalah usaha kesehatan yang bersifat preventif dengan cara memelihara dan mempertahankan atau memperbaiki kesehatan diri manusia. Menurut catatan World Health Organization tahun 2017, mencuci tangan dengan sabun mampu mengurangi 40 persen risiko diare dan 20 persen risiko infeksi saluran pernafasan akut. Tujuan penelitian ini untuk mengetahui pengaruh pendidikan kesehatan terhadap tingkat pengetahuan hand hygiene pada anak sekolah dasar di kelas 4 dan 5 SD Negeri 169 Palembang tahun 2019. Penelitian ini menggunakan jenis penelitian Pre Experimental Design dengan rancangan penelitian pre-post test design. Populasi pada penelitian ini adalah seluruh siswa kelas 4 dan 5 SD Negeri 169 Palembang yang berjumlah 133 siswa dengan jumlah sampel sebanyak 133 responden. Analisa data menggunakan analisa univariat dan bivariat. Hasil penelitian diketahui sebelum diberikan pendidikan kesehatan mayoritas responden pengetahuan kurang sebanyak 101 responden (75,9\%), sesudah diberikan pendidikan kesehatan responden pengetahuan baik sebanyak 94 responden (70,7\%). Hasil uji statistik ada pengaruh pendidikan kesehatan terhadap tingkat pengetahuan hand hygiene pada anak sekolah dasar di kelas IV dan V Sekolah Dasar Negeri 169 Palembang tahun 2019 ( $p$ value = 0,000 $<\alpha=0,05$ ). Diharapkan terus memberikan informasi pada siswa untuk membiasakan diri cuci tangan menggunakan sabun di lingkungan sekolah dan rumah, guna mencegah timbulnya penyakit yang disebabkan oleh tangan yang kotor.
\end{abstract}

Kata Kunci : Hand Hygiene, Pendidikan Kesehatan, Pengetahuan

\begin{abstract}
Hygiene is a preventive health effort by maintaining and maintaining or improving human health. According to 2017 World Health Organization records, washing hands with soap can reduce the risk of diarrhea by 40 percent and by 20 percent the risk of acute respiratory infections. The purpose of this study was to determine the effect of health education on the level of knowledge of hand hygiene in elementary school children in grades 4 and 5 of SD Negeri 169 Palembang in 2019. This study used a Pre Experimental Design research type with a pre-post test design research design. The population in this study were all 4th and 5th grade students of SD Negeri 169 Palembang, totaling 133 students with a total sample of 133 respondents. Data analysis used univariate and bivariate analysis. The results of the study found that before being given health education, the majority of respondents lacked knowledge as much as 101 respondents (75.9\%), after being given health education, respondents had good knowledge as many as 94 respondents (70.7\%). The results of the statistical test showed that there was an effect of health education on the level of knowledge of hand hygiene in elementary school children in grades IV and V of 169 Palembang State Elementary School in 2019 ( $p$ value $=0.000<\alpha=0.05$ ). It is expected that students will continue to provide information to students to get used to washing their hands using soap in the school and home environment, in order to prevent diseases caused by dirty hands.
\end{abstract}

Keywords

: Hand Hygiene, Health Education, Knowledge

Jurnal Kesehatan dan Pembangunan, Vol. 11, No. 22, Juli 2021 


\section{PENDAHULUAN}

Strategi Nasional Sanitasi Total berbasis Masyarakat (STBM) adalah aksi terpadu untuk menurunkan angka kejadian penyakit menular berbasis lingkungan termasuk diantaranya adalah diare dan kecacingan serta meningkatkan perilaku higienitas dan kualitas kehidupan masyarakat Indonesia. STBM merupakan aksi terpadu yang dapat mendukung tercapainya Millennium Development Goals tahun 2015 ke 4 yaitu menurunkan angka kesakitan dan kematian bayi dan anak merupakan salah satunya adalah dengan perilaku CTPS (Cuci Tangan Pakai Sabun) sehingga angka kematian dan penyebaran penyakit yang disebabkan oleh lingkungan dapat dikurangi. Saat ini kesadaran akan pentingnya perilaku higienis dan sanitasi di Indonesia masih relatif sangat rendah (Kemenkes RI dalam Rindafit, 2015)

Hygiene adalah usaha kesehatan yang bersifat preventif dengan cara memelihara dan mempertahankan atau memperbaiki kesehatan diri manusia. Hygiene dimulai dari membiasakan untuk mandi tiap hari, mencuci tangan, mencuci piring, membuang sampah dan semua hal yang berkenaan dengan kebersihan diri pribadi. Salah satu anggota tubuh yang sangat vital dalam mengelola makanan dan minuman adalah tangan. Melalui tangan, berbagai macam kemungkinan pencemaran (kontaminasi) terhadap makanan dan minuman dapat terjadi. Oleh karena itu, kebersihan tangan hal yang sangat utama, mulai dai membiasakan cuci tangan dengan sabun atau air hangat setiap kali selesai menggunakan kamar mandi/toilet, setelah merokok, hingga setelah bersin. Setelah mencuci tangan, tangan wajib dikeringkan dengan tisu atau mesin pengering (Parantika dan Hurdawaty, 2018).

Menurut catatan World Health Organization tahun 2017, mencuci tangan dengan sabun mampu mengurangi 40 persen risiko diare dan 20 persen risiko infeksi saluran pernafasan akut (WHO, 2017). Gerakan Nasional Sanitasi Total Berbasis Masyarakat dan cuci tangan dengan sabun, mulai dicanangkan oleh pemerintah. Gerakan yang dicanangkan adalah "Gerakan Nasional Cuci Tangan Pakai Sabun". Gerakan ini dilakukan sebagai bagian dari kebijakan pemerintah untuk pengendalian risiko penyakit yang berhubungan dengan lingkungan, seperti penyakit diare, penyakit kecacingan, dan tifoid yang sebenarnya dapat dicegah dengan kebiasaan buang air besar di jamban, penyediaan air minum dan kebiasaan mencuci tangan dengan sabun setelah buang air besar dan sebelum menjamah makanan". Gerakan serupa pernah dilakukan di Bangladesh bekerjasama dengan UNICEF, gerakan ini bertujuan untuk meningkatkan kebiasaan cuci tangan pada masyarakat, terutama sebelum menyiapkan makanan, sebelum makan, sebelum memberi makan pada anak, setelah buang air besar dan setelah membersihkan anus anak (Wantiyah, 2013)

Dalam menyelenggarakan misi peningkaan kesehatan dan pencegahan penyakit, kesehatan masyarakat ditopang oleh berbagai pilar, diantaranya adalah pendidikan atau promosi kesehaan. Sekolah merupakan perpanjangan tangan orang tua, bukan saja tempat menanamkan dan mengembangkan kemampuan hidup (life skills) untuk memasuki duni kerja. Untuk itu, sekolah juga harus menjadi lingkungan yang kondusif bagi terbentuknya dan berkembangnya perilaku hidup sehat, sebagai prasyarat untuk berkembangnya potensi anak didik secara optimal (Notoatmodjo dkk, 2012)

Cuci tangan sering dianggap sebagai hal yang sepele di masyarakat, padahal cuci tangan bisa memberi kontribusi pada peningkatan status kesehatan masyarakat. Berdasarkan fenomena yang ada terlihat bahwa anak-anak usia sekolah mempunyai kebiasaan kurang memperhatikan perlunya cuci tangan dalam kehidupan sehari-hari, terutama ketika di lingkungan sekolah. Mereka biasanya langsung makan makanan 
yang mereka beli di sekitar sekolah tanpa cuci tangan terlebih dahulu, padahal sebelumnya mereka bermain-main. Perilaku tersebut tentunya berpengaruh dan dapat memberikan kontribusi dalam terjadinya penyakit diare. Cuci tangan merupakan tehnik dasar yang paling penting dalam pencegahan dan pengontrolan penularan infeksi (Wantiyah dkk, 2013).

Upaya meningkatkan pemahaman dan kesadaran remaja dalam melakukan pencegahan cuci tangan dapat dilakukan dengan pemberian pendidikan kesehatan melalui penyuluhan kesehatan. Kegiatan pendidikan kesehatan yang dilakukan dengan menyebarkan pesan, menanamkan keyakinan, sehingga masyarakat tidak saja sadar, tahu dan mengerti tetapi juga mau dan bisa melakukan suatu anjuran yang ada hubunganya dengan kesehatan (Suryani dalam Rindafit, 2015).

Menurut hasil penelitian Rahmawati (2017) dengan judul pengaruh pendidikan kesehatan terhadap tingkat pengetahuan hand hygiene pada anak sekolah dasar di SD Muhammadiyah Senggotan. Hasil dari uji beda menunjukkan perbedaan nilai awal pretes dengan nilai akhir post-tes pada responden. Diperoleh hasil nilai $P$-value $<0.05(0.003<0.05)$ yang artinya terdapat perbedaan yang signifikan antara pre-tes dan post-tes setelah diberikan pendidikan kesehatan menggunakan metode demonstrasi dan media poster.

Berdasarkan data dari Sekolah Dasar Negeri 169 Palembang diketahui bahwa jumlah siswa tahun ajaran 2016/2017 kelas I sebanyak 77 siswa, kelas II berjumlah 68 siswa, kelas III sebanyak 71 siswa, kelas IV sebanyak 64, kelas V sebanyak 69 siswa.

Dari uraian diatas peneliti tertarik untuk melakukan penelitian mengenai Pengaruh pendidikan kesehatan terhadap tingkat pengetahuan hand hygiene pada anak sekolah dasar di kelas 4 dan 5 SD Negeri 169 Palembang tahun 2019.

\section{Desain Penelitian}

Penelitian ini menggunakan jenis penelitian Pre Experimental Design dengan rancangan penelitian pre-post test design yang dilakukan pada satu kelompok tanpa kelompok control. Kelompok subjek diobservasi sebelum dilakukan intervensi (pre-test) kemudian diobservasi lagi setelah intervensi (post-test). Intervensi yang diberikan berupa pemberian pendidikan kesehatan.

\section{Waktu penelitian}

Penelitian dilaksanakan pada tanggal 15 April - 17 April Tahun 2019

\section{Tempat Penelitian}

Penelitian ini dilaksanakan di SD Negeri 169 Palembang.

\section{Populasi Dan Sampel Populasi}

Populasi pada penelitian ini adalah seluruh siswa kelas 4 dan 5 SD Negeri 169 Palembang yang berjumlah 133 siswa.

\section{Sampel}

Teknik pengambilan sampel pada penelitian ini menggunakan total sampling, yaitu pengambilan semua anggota populasi untuk dijadikan sampel. Jadi sampel pada penelitian ini adalah seluruh siswa kelas 4 dan 5 SD Negeri 169 Palembang yang berjumlah 133 siswa.

\section{Teknik Pengambilan Sampel}

Teknik pengambilan sampel pada penelitian ini menggunakan total sampling, yaitu pengambilan semua anggota populasi untuk dijadikan sampel.

\section{Variabel Penelitian}

Variabel dalam penelitian ini adalah pengetahuan tentang hand hygiene sebelum dan sesudah diberikan pendidikan kesehatan.

\section{Pengumpulan data}

Jurnal Kesehatan dan Pembangunan, Vol. 11, No. 22, Juli 2021 
1. Analisa Data Univariat

2. Analisa Bivariat

\section{Data dan Cara Pengumpulan Data Data}

\section{Data primer}

Penelitian ini menggunakan data primer diperoleh dengan cara melakukan pengisian kuesioner dengan menggunakan lembar kuesioner.

\section{Data Sekunder}

Dalam penelitian ini data sekunder diperoleh melalui profil sekolah dasar SD Negeri 169 Palemabang, serta media massa berupa internet dan buku-buku yang berhubungan dengan penelitian ini.

\section{Cara Pengumpulan Data}

Dalam penelitian pengolahan data yang digunakan adalah dengan primer. Langkah-langkah dalam pengolahan data :

1. Editing (pemeriksaan data)

Merupakan pengecekan atau pengkoreksian data yang teah dikumpulkan karena kemungkinan data yang masuk atau data yang terkumpul itu logis dan meragukan. Tujuan editing adalah untuk menghilangkan kesalahan-kesalahan yang terdapat pada pencatat di lapangan dan bersifat koreksi.

\section{Coding (pengkodean)}

Merupakan pemberian kode-kode pada tiap-tiap data yang termasuk dalam kategori yang sama. Kode adalah isyarat yang dibuat dalam bentuk angka-angka / huruf-huruf yang memberikan petunjuk atau identitas pada suatu informasi atau data yang akan dibahas

3. Tabulasi (tabulasi data)

Merupakan membuat tabel-tabel yang berisikan data yang telah di beri kode, sesuai dengan analisis yang dibutuhkan.

4. Entry data (pemasukan data)

Pada tahap entry data, data dimasukkan kedalam sistem computer untuk diolah.

5. Cleaning data (pembersihan data)

Data yang telah dimasukkan diperiksa kembali sesuai dengan kriteria data. Langkah ini bertujuan untuk membersihkan data dari kesalahan.

\section{Teknik Analisis Data}

Analisa data adalah Kegiatan mengubah data hasil penelitian menjadi informasi yang dapat digunakan untuk mengambil kesimpulan dalam suatu penelitian. Adapun cara mengambil kesimpulan bisa dengan hipotesis maupun dengan estimasi hasil. Dalam penelitian ini analisa data dilakukan dengan dua cara yaitu:

\section{Analisa Univariat}

Pada anaisa univariat bertujuan untuk menjelaskan karakteristik setiap variabel penelitian (Notoatmodjo, 2012). Analisa univariat dilakukan dengan analisa distribusi frekuensi dan hasil statistik dari variabel yang diteliti meliputi mean, media, standar deviasi, nilai minimal dan maksimal. Di analisa univariat dilakukan untuk mengetahui distribusi frekuensi pengetahuan tentang hand hygiene sebelum dan sesudah diberikan pendidikan kesehatan.

\section{Analisa Bivariat}

Pada penelitian ini, analisis bivariat dilakukan dengan terlebih dahulu melakukan uji normalitas data menggunakan uji Shapiro-Wilk bila sampel kurang dari 50 atau uji Kolmogorov-Smirnov bila sampel lebih dari 50, dengan ketentuan jika $p$ value $\geq 0,05$ berarti data terdistribusi normal dan jika $p$ value $<0,05$ berarti data tidak terdistribusi normal. Setelah itu untuk uji pengaruh menggunakan uji statistik Paired Sample Test dengan tingkat kemaknaan alpha 0,05 bila data terdistribusi normal dan uji Wilcoxon bila data tidak terdistribusi normal dengan ketentuan jika $p$ value $<0,05$ berarti ada pengaruh dan jika jika $p$ value $\geq 0,05$ berarti tidak ada pengaruh (Dahlan, 2013).

Dengan keputusan jika $p$ value $\leq \alpha(0,05)$ maka Ha ditolak dan jika $p$ value $>\alpha(0,05)$ maka Ha diterima. Jadi dalam penelitian ini apabila nilai $\mathrm{p}$ value $\leq \alpha(0,05)$ berarti ada tidak ada pengaruh pendidikan kesehatan terhadap tingkat pengetahuan hand hygiene 
pada anak sekolah dasar dan apabila nilai $\mathrm{p}$ value $>\alpha(0,05)$ berarti tidak ada pengaruh pendidikan kesehatan terhadap tingkat pengetahuan hand hygiene pada anak sekolah dasar.

\section{HASL PENELITIAN DAN PEMBAHASAN}

\section{HASIL PENELITIAN}

\section{A. Analisis Univariat}

Analisis ini dilakukan untuk mengetahui distribusi frekuensi dari tiap-tiap variabel yaitu pengetahuan tentang hand hygiene sebelum dan sesudah diberikan pendidikan kesehatan.

\section{Pengetahuan tentang Hand Hygiene sebelum diberikan Pendidikan Kesehatan}

Dalam penelitian ini pengetahuan dikelompokkan menjadi 2 kategori yaitu baik (jika siswa dapat menjawab > 50\% pertanyaan dengan benar) dan kurang (jika siswa dapat menjawab $\leq 50 \%$ pertanyaan dengan benar). Pengetahuan sebelum diberikan pendidikan kesehatan dapat dilihat pada tabel dibawah ini:

Tabel 1.1

\section{Distribusi Frekuensi Pengetahuan \\ Sebelum Diberikan Pendidikan \\ Kesehatan di SD Negeri 169 Palembang Tahun 2019}

\begin{tabular}{cccc}
\hline No & Pengetahuan & Frekuensi & $\begin{array}{c}\text { Presentase } \\
(\boldsymbol{\%})\end{array}$ \\
\hline 1 & Baik & 32 & 24,1 \\
\hline 2 & Kurang & 101 & 75,9 \\
\hline & Total & 133 & 100 \\
\hline
\end{tabular}

Berdasarkan tabel 1.1 diatas menunjukkan bahwa dari 133 responden dengan pengetahuan baik sebanyak 32 responden $(24,1 \%)$ dan responden pengetahuan kurang sebanyak 101 responden $(75,9 \%)$.

\section{Pengetahuan tentang Hand Hygiene Sesudah Diberikan Pendidikan Kesehatan}

Dalam penelitian ini pengetahuan dikelompokkan menjadi 2 kategori yaitu baik (jika siswa dapat menjawab > 50\% pertanyaan dengan benar) dan kurang (jika siswa dapat menjawab $\leq 50 \%$ pertanyaan dengan benar). Pengetahuan sesudah diberikan pendidikan kesehatan dapat dilihat pada tabel dibawah ini:

\section{Tabel 4.2}

Distribusi Frekuensi Pengetahuan Sesudah Diberikan Pendidikan Kesehatan di SD Negeri 169 Palembang Tahun 2019

\begin{tabular}{|c|c|}
\hline No & $\begin{array}{ccc}\text { Pengetahuan Frekuensi } & \begin{array}{c}\text { Presentase } \\
(\%)\end{array}\end{array}$ \\
\hline 1 & Baik \\
\hline 2 & Kurang \\
\hline & Total \\
\hline $\begin{array}{l}\text { me } \\
\text { den } \\
\text { res } \\
\text { pen } \\
(29\end{array}$ & $\begin{array}{l}\text { Berdasarkan tabel } 4.2 \text { diatas } \\
\text { unjukkan bahwa dari } 133 \text { responden } \\
\text { gan pengetahuan baik sebanyak } 94 \\
\text { onden }(70,7 \%) \text { dan responden } \\
\text { getahuan kurang sebanyak } 39 \text { responden } \\
3 \%) \text {. }\end{array}$ \\
\hline
\end{tabular}

\section{B. Analisis Bivariat}

Analisis ini untuk mengetahui pengaruh pendidikan kesehatan terhadap tingkat pengetahuan hand hygiene pada anak sekolah dasar dengan uji statistik yang sesuai dengan tujuan penelitian, yakni uji paired sample t test sampel dengan taraf signifikan $\alpha=0,05$, dimana ketentuannya adalah jika nilai $\mathrm{p}$ value $>\alpha(0,05)$ berarti tidak ada pengaruh dan jika $\mathrm{p}$ value $<\alpha(0,05)$ berarti ada pengaruh. Berdasarkan hasil uji normalitas data didapatkan nilai $p$ value $=$ 0,104 (pre test) dan 0,091 (post test) yang berarti data berdistribusi normal. 


\section{Pengaruh Pendidikan Kesehatan} Terhadap Tingkat Pengetahuan Hand Hygiene Pada Anak Sekolah Dasar

Jumlah responden dalam penelitian ini adalah 133 orang. Pada analisis bivariat ini digunakan untuk mengetahui pengaruh pendidikan kesehatan terhadap tingkat pengetahuan hand hygiene pada anak sekolah dasar. Hasil penelitian dapat dilihat pada tabel 4.3 dibawah ini:

\section{Tabel 4.3}

Pengaruh Pendidikan Kesehatan

Terhadap Tingkat Pengetahuan Hand

Hygiene Pada Anak Sekolah Dasar di

Kelas 4 dan 5 SD Negeri 169 Palembang Palembang

\begin{tabular}{lcccc}
\hline Pengetahuan & $\mathrm{n}$ & Mean & $\mathrm{SD}$ & $\begin{array}{c}p \\
\text { value }\end{array}$ \\
\cline { 1 - 3 } Sebelum & \multirow{2}{*}{133} & 47,74 & 10,561 & 0,000 \\
\cline { 1 - 4 } & & 64,81 & 15,453 & \\
\hline
\end{tabular}

Berdasarkan tabel 4.3 di atas diketahui bahwa nilai rata-rata pengetahuan sebelum diberikan pendidikan kesehatan sebesar 47,74 dengan standar deviasi 10,561 sedangkan nilai rata-rata pengetahuan sesudah diberikan pendidikan kesehatan sebesar 64,81 dengan standar deviasi 15,453. Dari hasil uji statistik diketahui nilai $p$ value $=0,000<$ dari $\alpha=0,05$ sehingga dapat disimpulkan bahwa ada pengaruh pendidikan kesehatan terhadap tingkat pengetahuan hand hygiene pada anak sekolah dasar di kelas 4 dan 5 SD Negeri 169 Palembang tahun 2019.

\section{PEMBAHASAN}

Penelitian ini dilakukan di SD Negeri 169 Palembang pada tanggal 15 April - 17 April Tahun 2019. Populasi yang diambil dalam penelitian ini adalah semua siswa kelas 4 dan 5. Sampel pada penelitian ini adalah semua siswa kelas 4 dan 5 berjumlah 133 orang.

Selanjutnya data yang dikumpulkan diolah dan dilakukan analisis univariat dan bivariat. Pada analisis bivariat dengan menggunakan teknik analisis data yang digunakan yaitu analisis uji statistik uji paired sample $t$ test secara komputerisasi melalui SPSS.

\section{Pengaruh Pendidikan Kesehatan Terhadap Tingkat Pengetahuan Hand Hygiene Pada Anak Sekolah Dasar}

Hasil analisis univariat diketahui bahwa dari 133 responden dengan pengetahuan baik sebanyak 32 responden $(24,1 \%)$ dan responden pengetahuan kurang sebanyak 101 responden (75,9\%). Sesudah diberikan pendidikan kesehatan dari 133 responden dengan pengetahuan baik sebanyak 94 responden $(70,7 \%)$ dan responden pengetahuan kurang sebanyak 39 responden $(29,3 \%)$.

Hasil analisis bivariat diketahui nilai rata-rata pengetahuan sebelum diberikan pendidikan kesehatan sebesar 47,74 dengan standar deviasi 10,561 sedangkan nilai rata-rata pengetahuan sesudah diberikan pendidikan kesehatan sebesar 64,81 dengan standar deviasi 15,453. Dari hasil uji statistik diketahui nilai $p$ value $=0,000<$ dari $\alpha=0,05$ sehingga dapat disimpulkan bahwa ada pengaruh pendidikan kesehatan terhadap tingkat pengetahuan hand hygiene pada anak sekolah dasar di kelas 4 dan 5 SD Negeri 169 Palembang tahun 2019. Hasil penelitian ini sejalan dengan penelitian Rahmawati (2017) dengan judul pengaruh pendidikan kesehatan terhadap tingkat pengetahuan hand hygiene pada anak sekolah dasar di SD Muhammadiyah Senggotan. Hasil dari uji beda menunjukkan perbedaan nilai awal pre-tes dengan nilai akhir post-tes pada responden. Diperoleh hasil nilai $P$-value $<0.05(0.003<0.05)$ yang artinya terdapat perbedaan yang signifikan antara pre-tes dan post-tes setelah diberikan pendidikan kesehatan menggunakan metode demonstrasi dan media poster.

Penelitian ini sejalan dengan penelitian Hadiatma (2014) tentang Pengaruh pendidikan kesehatan tentang mencuci tangan terhadap tingkat pengetahuan dan 
perilaku mencuci tangan siswa SDN 01 Gonilan. Hasil penelitian diketahui terdapat perbedaan pengetahuan dan perilaku mencuci tangan antara kelompok eksperimen dengan kelompok kontrol.

Penelitian Septriani (2017) tentang pengaruh metode pembelajaran bernyanyi terhadap pelaksanaan cuci tangan pada anak usia pra sekolah di RA Baiturrahi, Cibeber tahun 2017. Hasil penelitian menunjukkan perbedaan pelaksanaan cuci tangan pada kelompok intervensi sesudah diberikan metode pembelajaran bernyanyi dan kelompok control sesudah dengan hasil uji man whitney diperoleh nilai $p$ value $=0,001$

Penelitian Pratiwi (2017) tentang pengetahuan dan perilaku cuci tangan pada anak sekolah dasar di Kota Malang. Hasil penelitian diketahui distribusi frekuensi pengetahuan dan perilaku cuci tangan pada anak sekolah dasar di Kota Malam menunjukkan sebanyak $65 \%$ pengetahuan baik dan 59\% mempunyai perilaku cuci tangan yang cukup baik

Hasil penelitian ini juga sejalan dengan penelitian Randafit (2015) tentang efektifitas pendidikan kesehatan terhadap praktik cuci tangan pada anak prasekolah. Hasil penelitian menunjukkan bahwa hampir seluruh responden tidak melakukan praktik cuci tangan dengan baik sebelum diberikan pendidikan kesehatan tentang cuci tangan yaitu sebanyak 26 responden $(83,9 \%)$ dan hampir seluruh responden melakukan praktik cuci tangan dengan baik sesudah diberikan pendidikan kesehatan tentang cuci tangan yaitu sebanyak 25 responden (80,6\%). Hasil analisa menunjukkan adanya peningkatan nilai rata-rata (mean) pada praktik cuci tangan dari sebelum diberikan pendidikan kesehatan sebesar 1,29 dan sesudah diberikan pendidikan kesehatan menjadi 3,19, hal ini menunjukkan bahwa terdapat efektifitas pendidikan kesehatan terhadap praktik cuci tangan pada anak prasekolah.

Penelitian Raharjo (2017) tentang pengaruh pendidikan kesehatan dengan media leaflet terhadap perilaku Cuci Tangan
Pengunjung di Rumah Sakit Umum Bali Royal. Hasil uji statistik Mann Whitney U test menunjukkan ada perbedaan perilaku pengunjung mencuci tangan antara kelompok perlakuan dan kontrol dengan $\mathrm{p}=0,001$.

Hasil penelitian Hariyadi (2016) tentang pengaruh pendidikan kesehatan dengan metode ceramah dan demonstrasi terhadap pengatahuan mencuci tangan pada siswa SDN Segulung 02 dan SDN Segulung 05. Hasil penelitian pengetahuan siswa sebelum diberikan intervensi berada pada 66,56 dengan kategori cukup. Setelah diberi intervensi mengalami peningkatan yaitu 97,19 dengan kategori sangat baik. Pada kelompok kontrol pengetahuan siswa yaitu 84,06 dengan kategori sangat baik. Maka hasil penelitian ini adalah ada perbedaan pengatahuan antara kelompok perlakuan dan kelompok kontrol dengan hasil kemaknaan $\rho$ $=0,000<\alpha=0,05$.

Penelitian Sekarwati (2017) tentang pengaruh pendidikan kesehatan terhadap perilaku cuci tangan pakai sabun pada Siswa Sekolah Dasar Negeri Kalasan 1, Kalasan Sleman Yogyakarta. Hasil penelitian menunjukan nilai anlisis Bivariate dengan rumus $\mathrm{T}$-test menunjukan bahwa terdapat pengaruh yang signifi kan antara pengaruh pendidikan kesehatan terhadap perilaku cuci tangan pakai sabun pada Siswa Sekolah Dasar Negeri Kalasan 1, Kalasan Sleman Yogyakarta, diketahui Sig (2-tailed 0,000).

Penelitian Subagyo (2018) tentang pengaruh pendidikan kesehatan CTPS terhadap pengetahuan dan perilaku CTPS siswa di SDN 06 Wonorejo Kabupaten Kayong utara. Hasil uji statistik pengetahuan menggunakan uji Marginal Homogeneity didapatkan nilai $\mathrm{p}$ yaitu 0,000 . Terdapat pengaruh pendidikan kesehatan CTPS terhadap pengetahuan dan perilaku siswa di SDN 06 Wonorejo Kabupaten Kayong Utara. Penelitian Kahusadi (2018) mengenai pengaruh penyuluhan kebersihan tangan (hand hygiene) terhadap perilaku siswa sebelum dan sesudah penyuluhan di SD GMIM 76 Maliambao Kecamatan 
Likupang Barat. erdasarkan hasil analisis data diperoleh nilai $t$ hitung untuk pengetahuan sebelum -sesudah penyuluhan yaitu thitung $=-5,821$ dengan pvalue $=0,000$ artinya terdapat perbedaan yang signifikan antara pengetahuan sebelumsesudah dilaksanakannya penyuluhan. Sedangkan untuk sikap sebelum-sesudah penyuluhan yaitu didapatkan thitung $=-4,602$ dan pvalue $=0,000$ yang artinya terdapat perbedaan yang signifikan antara sikap responden sebelum dan sesudah dilaksankan penyuluhan kesehatan tentang kebersihan tangan di SD GMIM 76 Maliambao.

Pengetahuan yang kurang dapat disebabkan karena kurangnya informasi yang diperoleh. Pemberian informasi dalam bentuk pendidikan kesehatan merupakan suatu proses yang bermanfaat untuk menciptakan kondisi yang mempengaruhi perilaku individu. Perilaku yang diharapkan tidak terbatas pada peningkatan pengetahuan, namun menciptakan sikap yang positif terhadap pesan yang disampaikan (Junios \& Rina, 2014).

Hasil penelitian ini sejalan dengan pendapat Maryunani (2013), perilaku mencuci tangan adalah suatu aktivitas, tindakan mencucin tangan yang dikerjakan oleh individu yang dapat diamati secara langsung maupun tidak langsung. Mencuci tangan adalah kegiatan membersihkan bagian telapak, punggung tangan dan jari agar bersih dari kotoran dan membunuh kuman penyebab penyakit yang merugikan kesehatan manusia seta membuat tangan menjadi harum baunya

Menurut Notoatmodjo (2009), media pendidikan kesehatan pada hakikatnya adalah alat bantu pendidikan (AVA). Disebut media pendidikan karena alat-alat tersebut merupakan alat saluran (channel) untuk menyampaikan kesehatan karena alat-alat tersebut digunakan untuk mempermudah penerimaan pesan-pesan kesehatan bagi masyarakat atau "klien".

Berdasarkan hasil penelitian, teori dan penelitian terkait maka peneliti berasumsi bahwa pemberian pendidikan kesehatan pada anak dapat meningkatkan pengetahuan siswa mengenai hand hygiene. Dengan memberikan pendidikan kesehatan akan menambah informasi beserta penjelasan dan pengalaman siswa dalam mempraktekkan cuci tangan yang baik dan benar untuk mencegah kontaminasi dengan mikroorganisme yang ada di tangan.

\section{KESIMPULAN DAN SARAN}

\section{Kesimpulan}

Dari hasil penelitian yang telah diuraikan sebelumnya, maka dapat ditarik kesimpulan sebagai berikut :

1. Distribusi frekuensi sebelum diberikan pendidikan kesehatan responden dengan pengetahuan baik sebanyak 32 responden $(24,1 \%)$ dan responden pengetahuan kurang sebanyak 101 responden $(75,9 \%)$.

2. Distribusi frekuensi sesudah diberikan pendidikan responden dengan pengetahuan baik sebanyak 94 responden $(70,7 \%)$ dan responden pengetahuan kurang sebanyak 39 responden $(29,3 \%)$.

3. Ada pengaruh pendidikan kesehatan terhadap tingkat pengetahuan hand hygiene pada anak sekolah dasar di kelas IV dan V Sekolah Dasar Negeri 169 Palembang tahun 2019 ( $p$ value $=0,000$ $<\alpha=0,05$ )

\section{Saran}

\section{Bagi Pihak Sekolah}

Diharapkan terus memberikan informasi pada siswa untuk membiasakan diri cuci tangan menggunakan sabun di lingkungan sekolah dan rumah, guna mencegah timbulnya penyakit yang disebabkan oleh tangan yang kotor. Keberhasilan cuci tangan pakai sabun bukan hanya ditunjang oleh perilaku cuci tangan saja, namun juga oleh adanya sarana dan prasarana yang diperlukan dalam menjaga keberlangsungan kegiatan 
cuci tangan, seperti sekolah menyediakan wastafel dan/sabun untuk cuci tangan, serta post/gambar cara mencuci tangan.

\section{Bagi Institusi Pendidikan}

Hasil penelitian ini dapat dijadikan sebagai bahan referensi dan menambah kepustakaan di STIKES Mitra Adiguna Palembang khususnya jurnal-jurnal dan Karya Tulis Ilmiah berkaitan dengan hand hygiene.

\section{Bagi Peneliti Selanjutnya}

Untuk meningkatkan kualitas hasil penelitian program hand hygiene, pada penelitian selanjutnya perlu dipertimbangkan penambahan jumlah sampel atau mencoba menerapkan tehnik-tehnik yang lain. Peneliti menganjurkan kepada peneliti selanjutnya untuk meneliti variabel, sampel maupun desain penelitian yang berbeda.

\section{DAFTAR PUSTAKA}

Budiman \& Riyanto, A. 2014. Kapita Selekta Kuesioner Pengetahuan dan Sikap Dalam Penelitian Kesehatan. Jakarta: Salemba Medika.

Hadiatama. 2013. Pengaruh Pendidikan Kesehatan Terhadap Perilaku Mencuci UMS Tangan Siswa Sekolah Dasar. Jurnal:

Maryunani, Anik. 2013. Perilaku Hidup Bersih dan Sehat (PHBS). Jakarta: Trans Info Media.

Mubarak, W.I. 2011. Promosi Kesehatan : Sebuah Pengantar Proses Belajar Mengajar dalam Pendidikan. Yogyakarta : Graha Ilmu.

Notoatmodjo, Soekidjo. 2012. Promosi Kesehatan dan Ilmu Perilaku. Jakarta: Rineka Cipta.
2012. Metodologi

Penelitian Kesehatan. Jakarta : Rineka Cipta.

.2009. Kesehatan

Masyarakat Ilmu dan Seni. Edisi Revisi Jakarta. Rineka Cipta.

Potter \& Perry. 2010. Buku Ajar Fundamental Keperawatan : Konsep, Proses \& Praktek. Jakarta : EGC

Parantika dan Hurdawaty. 2018. Sanitasi Hygiene dan Keselamatan Kerja. Jakarta: Erlangga

Profil SD Negeri 169 Palembang Tahun 2019.

Rahmawati Diah. 2017. Pengaruh Pendidikan Kesehatan terhadap tingkat pengetahuan hand hygiene pada anak sekolah dasar di SD Muhammadiyah Senggotan. Jurnal. Univ. Muhammadiyah Yogykarta.

Rindafit. 2015. Efektivitas Pendidikan Kesehatan Terhadap Praktik Cuci Tangan Pada Anak Prasekolah di PAUD Darunjannah Tamansari Wuluhan Jember. Jurnal. STIKES Jember.

Wantiyah dkk. 2013. Hubungan antara perilaku mencuci tangan dengan insiden diare pada anak usia sekolah di Kabupaten Jember. Jurnal. Tegal: Univ. Jember

WHO. 2017. Pencegahan Penyakit dengan Kebersihan Tangan. Online at http://WHO-hand-hygiene-html// diakses tanggal 11 Maret 2019 